\title{
ADAPTING COASTS TO CLIMATIC FUTURES. AN AUSTRALIAN PERSPECTIVE
}

Marcello Sano, Scott Baum, Marcus Bussey, Bill Carter, Florence Crick, Aliasghar Golshani, Darryl Low Choy, Russell Richards, Anne Roiko, Silvia Serrao-Neumann, Kristen Splinter, Tim Smith, Rodger Tomlinson

In coastal management under climatic pressures, the final aim of vulnerability assessments, system thinking or scenario planning exercises is to inform the identification of the most appropriate adaptation options for communities under risk of coastal hazards and climate change. In this paper we show how we combined these techniques for coastal settlements adaptation in South East Queensland, one of the most populated Australian regions, including: (i) the use of suburb-level mapping and numerical modelling to identify and assess vulnerability hotspots (ii) the development and testing of systems thinking and bayesian modelling techniques to explore adaptation pathways and the adaptive capacity of coastal communities and (iii) the use of scenario planning techniques to test adaptation options in an uncertain future. We show how these outcomes were used to develop a range of research-based adaptation policies, programs and actions and to inform the preparation of practical guidance for councils across Queensland.

Keywords: vulnerability, systems thinking, scenario planning, adaptation options, coastal hazards, climate change

\section{INTRODUCTION}

\section{South East Queensland, coastal hazards and climate change}

South East Queensland (SEQ) (figure 1) is one of the most developed and fastest growing coastal regions in Australia. This trend is set to continue as its population, currently around 2.8 million people, is expected to grow by approximately $50 \%$ in the next 20 years (Queensland Government, 2008). SEQ's coastal settlements are extremely vulnerable to sea-level rise (SLR) and extreme sea levels associated with storm tides (Castelle et al., 2007; Wang et al., 2010; Treloar et al., 2010). The SEQ coastal zone, from the northern boundary of the Sunshine Coast to the Queensland-New South Wales border, has a linear extension of around $280 \mathrm{~km}$. However, the total length of the shores exposed to changing sea water level is approximately $1,900 \mathrm{~km}$ including numerous natural waterways and artificial canals extending landwards from the coastline (Sharples et al. 2009).

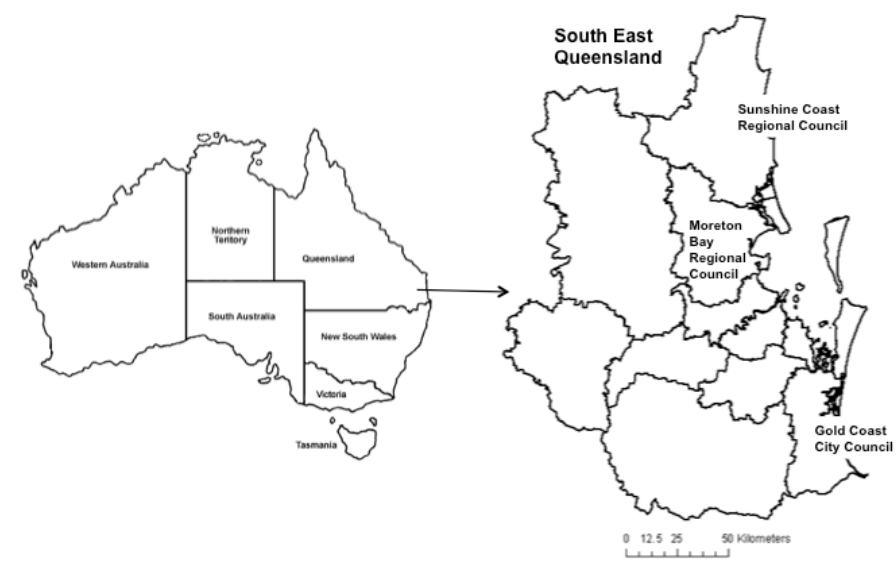

Figure 1 Location of SEQ within Australia and the coastal councils used as case study areas

The high concentration of population within the coastal zone as well as its exposure to climatic drivers such as sea level rise and extreme storms has prompted the IPCC in its Fourth Assessment Report to explicitly identify SEQ as highly vulnerable to the impacts of climate change (IPCC, 2007). While global mean sea level has risen at a rate of about $1.7 \mathrm{~mm}$ per year in the last two centuries, measurements in SEQ show a SLR of approximately $3 \mathrm{~mm}$ per year based on observations of the last two decades (NTC-BOM, 2011). Current projections based on the IPCC AR4 suggest a global worstcase scenario of SLR of around $60 \mathrm{~cm}$ by 2100 ; these figures, combined with regional variations from the global averages, are suggesting a SLR for Eastern Australia of around $80 \mathrm{~cm}$ by 2100 (CSIRO, 2011). SLR is not the only impact of a changing climate, with potential changes in average wave 
conditions and extreme weather events. In SEQ the average wave climate, the frequency of extreme events and consequently the transport of sediments and ultimately the shape of the coast are mainly driven by two types of storms: tropical cyclones and east coast lows. Both types of events have been responsible for extreme erosion, storm surges and floods in the past; future changes are still uncertain and are currently under investigation (Abbs, 2009; Hemer et al., 2009).

\section{Coastal planning and management in SEQ}

SLR, changing wave climate and extreme storms can exacerbate the already complex issue of managing human settlements and infrastructure on dynamic coastal environments. The SEQ coastal management framework includes a range of policies, plans and strategies issued by the three tiers of government. While the federal government has a limited direct role in coastal zone management, most of the power is in the hands of the States. For instance, the federal government has released a Commonwealth Coastal Policy in 1995 and a National Cooperative Approach to ICZM in 2006, both instruments adopted as non-statutory guidance by the States. On the other hand, in SEQ, the Government of Queensland, one of Australia's eight States and Territories, has the responsibility for natural resource management and statutory land use planning, including coastal zone management. This includes the preparation of the Queensland Coastal Plan under the Coastal Zone Management Act of 1995. This plan includes specific provisions related with climate change, such as the adaptation of planning in high hazard areas by developing a specific and compulsory Coastal Hazard Adaptation Strategy. At the local level of government, Councils are responsible for integrating State coastal policies into local instruments including planning schemes, coastal strategies (e.g. the Sunshine Coast Waterways and Coastal Management Strategy) and shoreline erosion management plans (e.g. the Gold Coast Shoreline Management Plan); this includes the development of the above mentioned Coastal Hazard Adaptation Strategy for areas at risk. At the time of writing (September 2012) the Queensland Coastal Plan has gone under a review process, which may change some of the mentioned requirements.

\section{Structure of this paper}

This paper showcases a range of connected research activities carried out to inform coastal adaptation in SEQ and the rest of the State. The first part of the paper reports on the assessment of vulnerability at the regional and local scales. The following sections report on our research into adaptation, including the exploration of broad adaptation pathways, the identification of adaptive capacity determinants and a scenario planning testing of specific adaptation options. This process has informed the development of a range of research-based coastal adaptation policies, programs and actions which in turn, informed the development of practical guidance for Coastal councils across Queensland.

\section{VULNERABILITY HOTSPOTS}

\section{Vulnerability concepts}

A spatial assessment was carried out to determine vulnerability hotspots across the SEQ coastal areas (Crick et al. 2011). For this purpose we used the IPCC AR4 concept of vulnerability as a combination of exposure, sensitivity and adaptive capacity. Differences in vulnerability were then mapped at the suburb scale. In this approach, exposure refers to the expected changes to climatic stimuli in a given location. Together, exposure and sensitivity produce the potential impacts of climate change, which can be attenuated by the individual or system's adaptive capacity. Adaptive capacity refers to the ability or potential to respond successfully to climate variability/change, including adjustments in behaviour, resources and technologies.

\section{Vulnerability hotspots in SEQ}

The assessment used here was based on a combination of sets of indicators of exposure, sensitivity and adaptive capacity using the suburb as a spatial management unit for data representation. The selection of appropriate indicators for each of these components was informed by the existing literature on vulnerability assessment and mapping (e.g. Cutter et al, 2000; Rygel et al, 2006), in particular the earlier work undertaken by Preston et al (2008), subject to the availability of data for disaggregated spatial units in SEQ. While the existing literature on vulnerability to extreme weather events provides several examples of both simple and complex index building routines, this study adopted a method of index development used by Baum et al (2009) and originally based on Langlois and Kitchen (2001). using a coastal vulnerability index (CVI) based on: 
Where:

- $\mathrm{E}_{\mathrm{i}}$ is the proportion of the suburb at risk from $1 \mathrm{~m}$ sea level rise.

- $\mathrm{C}_{\mathrm{ij}}$ is the standardised score for component $\mathrm{i}$ for suburb $\mathrm{j}^{*}$ after Principal Component Analysis.

Analysed datasets included in $\mathrm{C}_{\mathrm{ij}}$ cover both descriptors of sensitivity and adaptive capacity available at the Australian Bureau of Statistics and other sources, at the suburb level:

1. Geomorphologic sensitivity (Smartline dataset)

2. Percentage of population completing high school

3. Percentage of population that speaks language other than English

4. Percentage of households with internet access

5. Medium household income

6. Labour force participation rate

7. Average household size

8. Percentage of single parent families

9. Home ownership

10. Households with no cars

11. Unemployment rate

12. Percentage of people who need assistance

13. Percentage of people living at the same address as 1 year ago

14. Percentage of population doing voluntary work

The following map (on the left) shows the distribution of vulnerability across South East Queensland coastal suburbs, where coastal suburbs are all those in contact with tidal waters (figure 2). Palm Beach, on the Gold Coast, was the hotspot chosen for detailed analysis.
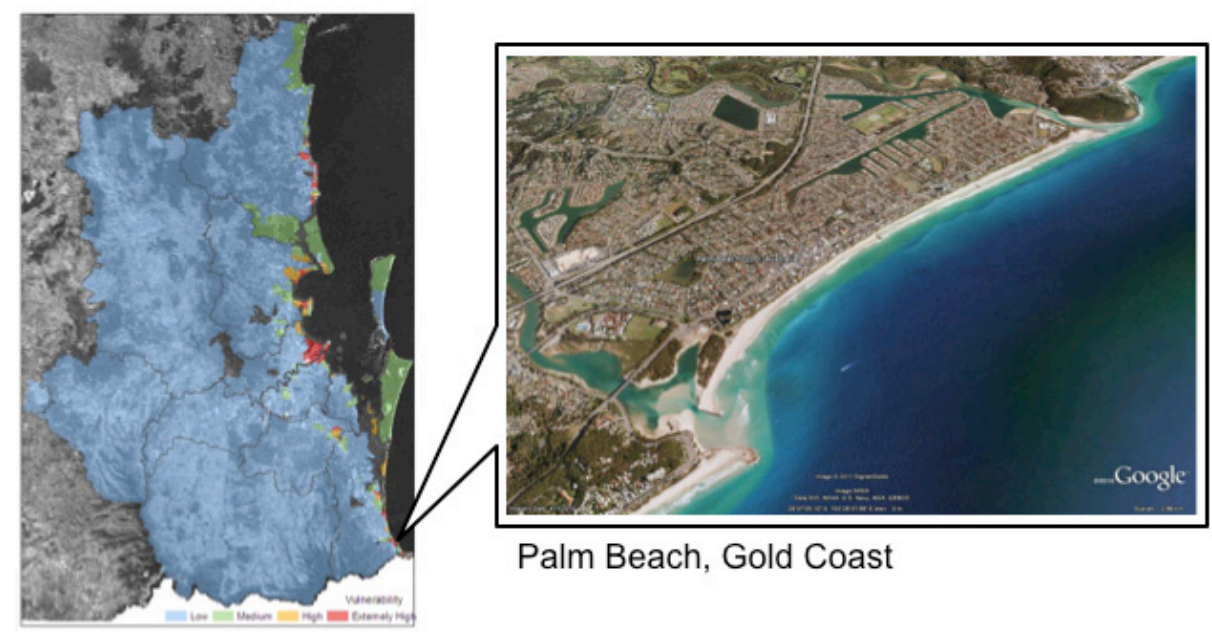

Palm Beach, Gold Coast

Figure 2. Vulnerability mapping identifying Palm Beach in the Gold Coast as a hotspot. This location was then used for further analysis.

\section{Local vulnerability}

The regional vulnerability assessment was particularly useful to identify hotspots of vulnerability at the local scale. Palm Beach, in the Gold Coast, is one of the most vulnerable areas of SEQ and was chosen for a more detailed assessment, the details of which are published in Sano et al (2011). Palm Beach is a $5 \mathrm{~km}$ coastal stretch in the central Gold Coast, Australia (Figure 2), where sedimentary systems and human settlements are especially exposed to the impacts of extreme storms. In the area, the increasing popularity of coastal living has resulted in increased levels in coastal development, often poorly planned with little consideration of the potential for erosion of the beaches. During the last century there have been several periods of intensely active cyclonic and storm activity that have tested the 
defenses of coastal infrastructure built on the active area of the beach. The worst impacts of erosive events and structural damage to properties in Palm Beach has occurred in 1967, 1972 and 1974. Storms in May 1996 and as recently as May 2009 have also highlighted the vulnerability of this section of the coast. The coast is protected by a semi-buried seawall which is the last resort for coastal protetcion, a one-of-a-kind approach combining beach nourishment and dune revegetation on top of a defence structure.

The detailed assessment covered: (i) the exposure to changing sea levels and storms by assessing the impact of sea level rise on already catastrophic extreme events using a hydrodynamic model (MIKE21) forced by a specific re-constructed storm of the past combined with future sea level rise scenarios; (ii) the assessment of the impact of sea level rise on beach erosion during the same extreme event (ECL of May 2009) using XBEACH, a morphodynamic model, combined with future sea level rise scenarios; (iii) the assessment of the adaptive capacity of the coastal settlement, as a function of the socioeconomic profile of the area of study based on a socio-economic disadvantage. The physical assessment is based on the current situation and on two scenarios of sea level rise: $0.5 \mathrm{~m}$ by 2050 and 1 $\mathrm{m}$ by 2100 . Results under sea level rise show an increase in the net storm surge elevation and erosion scenarios up to the boulder wall in both cases of SLR. Details are reported in (Sano et al. 2011).

As a next step to the vulnerability assessment, we looked into coastal hazards and climate change adaptation, including the exploration of broad pathways for adaptation, adaptive capacity determinants and a final identification and testing of specific adaptation options.

\section{ADAPTATION PATHWAYS AND ADAPTIVE CAPACITY}

The exploration of adaptation pathways and adaptive capacity determinants in coastal adaptation was used to inform the development of specific adaptation options and a final adaptation framework described in the next sections. The exercise was conducted in three different coastal localities: Gold Coast City Council, Sunshine Coast Regional Council and Moreton Bay Regional Council. The methodology used to explore adaptation pathways and adaptive capacity is based on previous research related to stakeholder engagement (Lynam et al. 2007; Voinov \& Bousquet 2010), system conceptualization (Elias 2008, Smith et al. 2009) and climate change adaptation (Holman et al., 2005; Giupponi et al. 2008). Selected stakeholders were engaged in workshops leading to the development of models describing adaptation pathways and adaptive capacity determinants, using techniques based on systems thinking and bayesian modelling (see Richards et al, 2012 for details). Workshops in coastal councils were carried out from September to December 2010 and involved approximately 40 participants.

\section{System conceptualization}

The system conceptualization process was initiated by presenting the participants with a few predetermined climatic and non climatic 'drivers of change' (e.g. sea level rise, increasing storm surges, increasing rainfall, and population growth). Participants were then asked to identify elements of their system that would be affected by these drivers, how these elements influenced other components of the system, as well as possible or actual adaptive responses. These elements were recorded on a large sheet of paper using coloured 'post-it' notes. The participants were also directed to identify connections between elements in the form of directional associations. This resulted in a system conceptualization or group mental model (figure 3). 


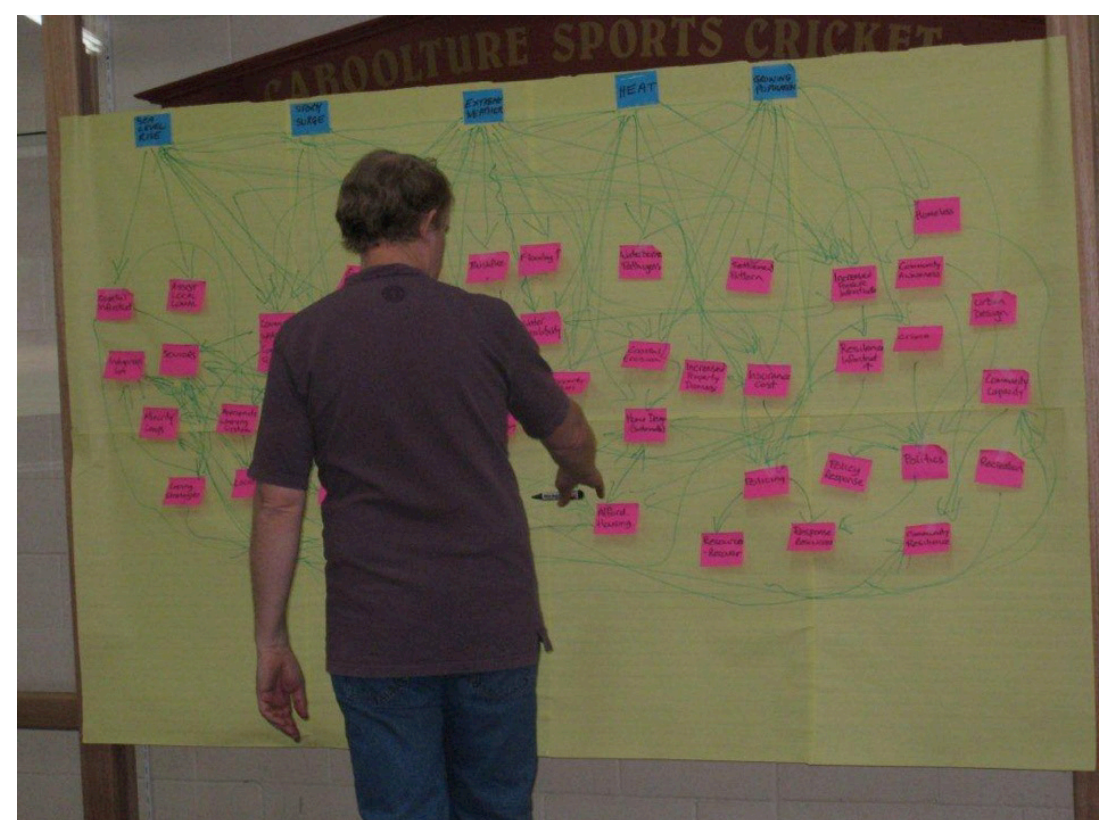

Figure 3. Butcher paper and post-It notes are used to build a shared model of the system with stakeholders. This model represents the Gold Coast case study area.

In parallel with capturing the system conceptualization model on paper, it was also captured digitally using the software platform VENSIM (www.venism.com). The overall system conceptualization was achieved under the guidance of three facilitators. One facilitator was in charge of stimulating the group to identify elements of, and connections within, the system; another recorded the proffered elements for addition to the record, while a third recorded the conceptualization using VENSIM. The result of this part of the workshop included a system conceptualization model recorded on paper and its translation into an interactive computer model (Figure 4).

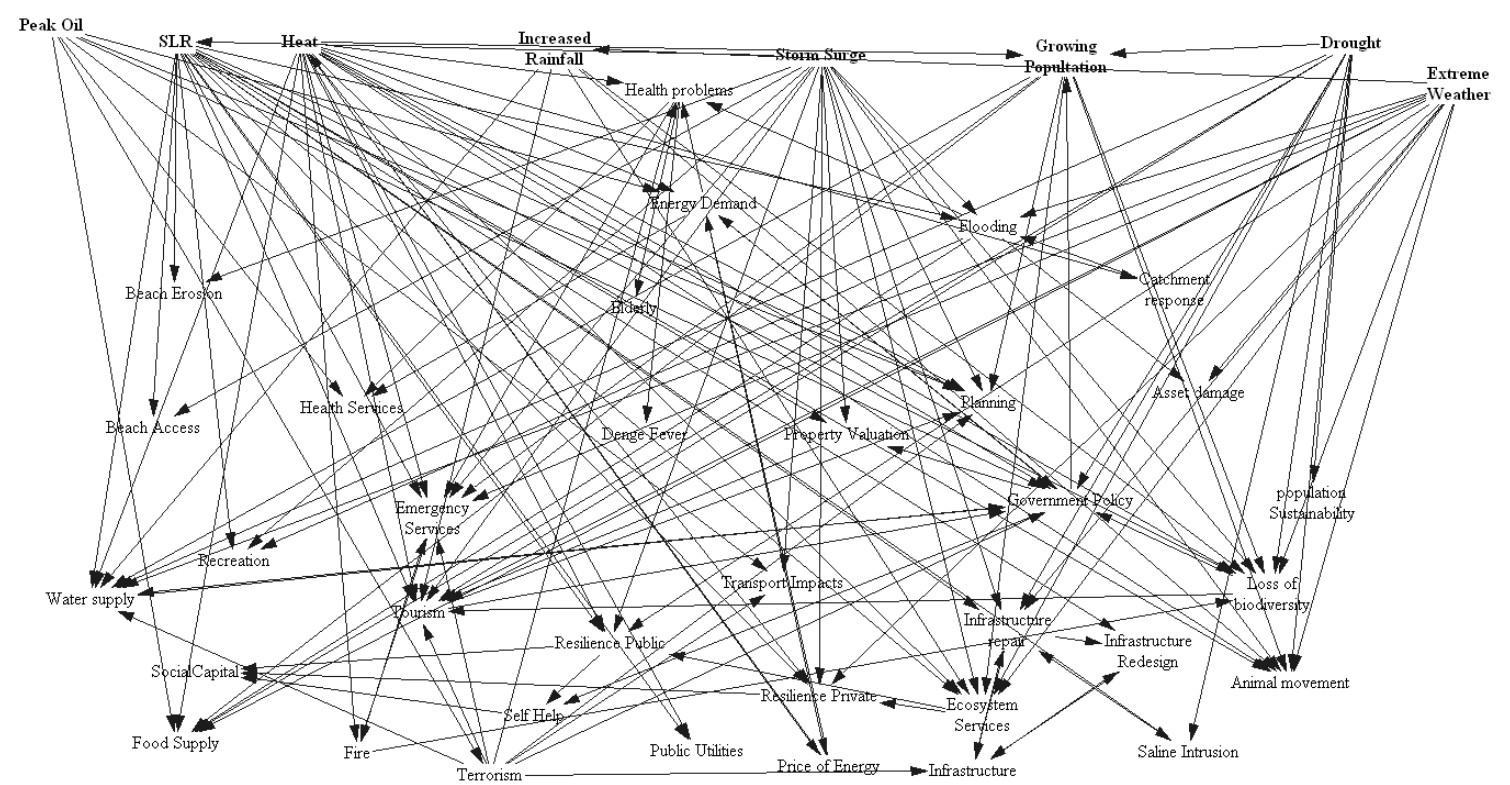

Figure 4. VENSIM, a systems thinking software, is used to represent and analyse conceptual models. This model represents the Gold Coast case study area.

\section{Structural analysis of system models}

These conceptualization models were then analysed to identify critical elements of the system during and after the workshop. During the workshop, visual assessment and expert judgment was complemented by the use of the "Tree Analysis" tools within VENSIM (i.e. analysis of direct and 
indirect drivers) to highlight critical elements within the system. After the workshops, structural analysis was performed to address the identification of adaptation pathways, using the complementary software package INFLUENCE (Walker 1996, Noble \& Walker 2006). The application of INFLUENCE enables analysis across a number of VENSIM models to classify system elements as either: influential, relay, resultant or having low influence, following a classification system proposed by Godet (1994). Results of this process showed a wide range of adaptation pathways identified by stakeholders across the three local government areas including (i) upgrade of coastal defense infrastructure against sea level rise (ii) adaptation of urban planning near the coast, including mechanisms for retreat (iii) changing design standards for houses and infrastructure to accommodate change (iv) improvement of emergency evacuation procedures. These results were used to inform specific adaptation options, some of which were tested using a scenario planning approach, described later in this paper.

\section{Bayesian modelling of adaptive capacity}

In order to identify adaptive capacity determinants, adaptation pathways were further explored during the workshops by testing a method called Bayesian Belief Networks (Charniak, 1991; Varis and Kuikka, 1997; Kjaerulff and Madsen, 2008) to identify determinants of adaptive capacity. Based on the selection of relevant adaptation pathways identified by the system conceptualization exercise previously described, stakeholders developed an a-cyclical (i.e. uni-directional) multi-level hierarchical tree highlighting the cause-and-effect relationships acting on the 'critical' issue. This information was then used to model the behaviour of the system and to identify critical determinants of adaptive capacity. This approach allowed the identification of a set of variables that could be correlated with the current adaptive capacity of SEQ's coastal areas to climate change, including infrastructure maintenance, emergency response to extreme events, and socio-economic characteristics of the region. For example, in the Gold Coast municipal area, the capacity to maintain current coastal infrastructure was a major concern for workshop participants involved in the planning sector. The subsequent BBN that was developed around this issue highlighted that coastal infrastructure was dependent on a combination of socio-economic and environmental factors: (i) the availability of funds for maintaining the infrastructure, (ii) the role of government policies and (iii) changing exposure to extreme events (figure 5). Details of this approach are published in Richards et al. (2012).

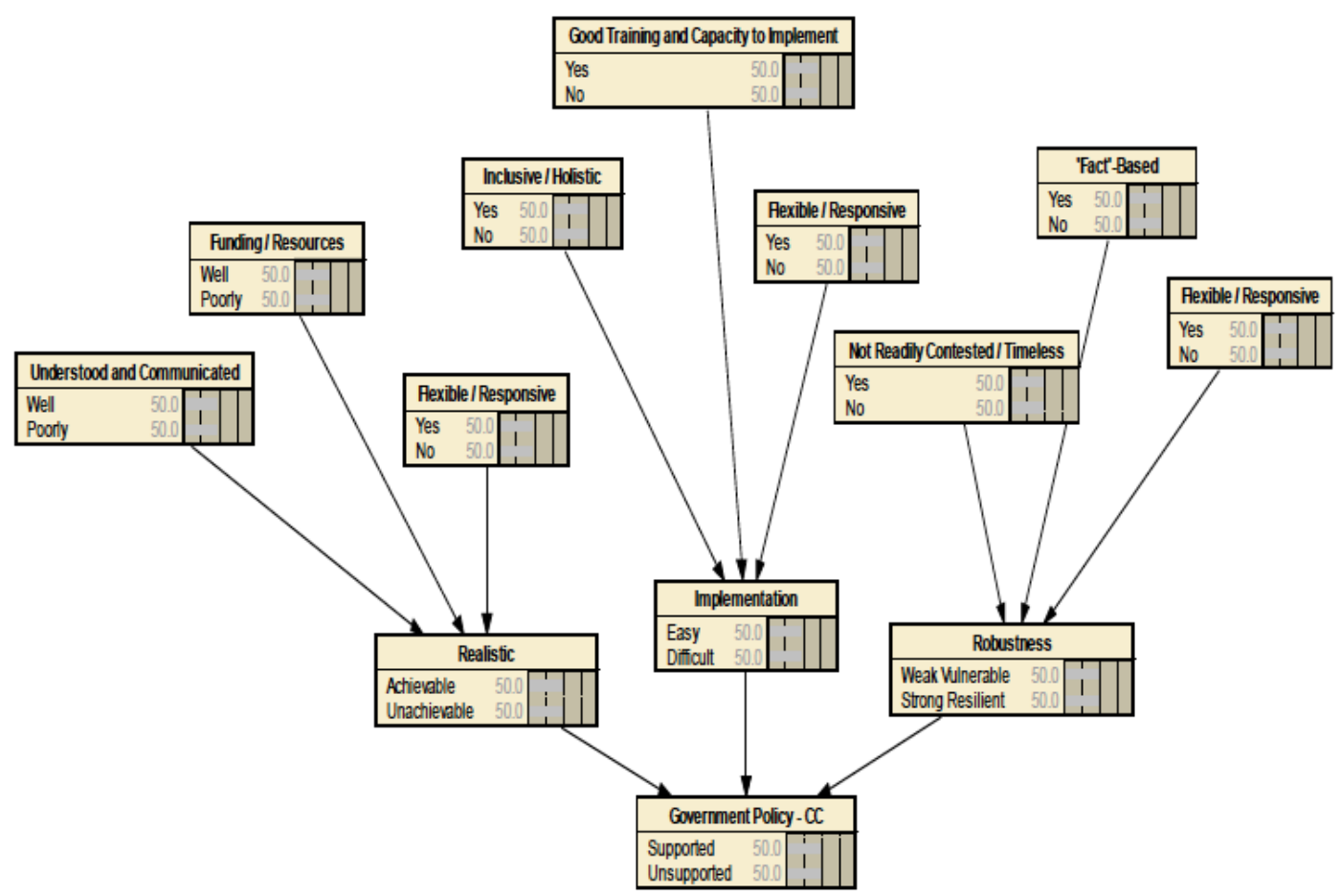

Figure 5. Bayesian modelling of the adaptive capacity of Gold Coast City Council to develop infrastructure policy in response to climate change 


\section{DEVELOPMENT AND TESTING OF ADAPTATION OPTIONS}

\section{Scenario planning}

The process described in the previous sections was useful to inform the development of specific coastal adaptation options. Some of these were employed for a scenario planning testing during a second round of workshops with the same stakeholder group. Scenario planning is a strategic approach, which can be used to develop a science-based decision making framework in the face of high uncertainty and low controllability (Peterson et al, 2003). It provides a systematic approach for the development and testing of plans, strategies and policies in an uncertain environment through the creation of possible futures to test them in (O'Brien, 2000). Scenario planning creates possible futures to inform present decisionmaking. In our research we used scenario planning in hypothetical case study areas in order to avoid conflicts and biases within the stakeholder group and undesired media coverage. We tested two scenarios on a range of hypothetical coastal locations:

1. "Shared Path" scenario, characterized by extremely high levels of community acceptance of responsibility and involvement in governance and in the management of community affairs operating in a political system offering a high degree of inclusive governance for its citizens.

2. "Free Ride" scenario, characterized by extremely low levels of community responsibility and involvement in governance and in the management of community affairs that operate in a political system offering a high degree of exclusive governance for its citizens.

Hypothetical locations, developed on real information masked behind altered maps and fake names, again to avoid conflicts and biases within the stakeholder group and undesired media coverage, included (Low Choy et al 2011):

- "Sandy Shores", a beachfront high-rise holiday destination, direct coastal location with high amenity and property values and high population density (including seasonal variations), based on Main Beach/Southport/Labrador suburbs, Gold Coast City Council (figure 5).

- "Blue Waters", a canal estate, extensive residential precincts largely with water focussed lifestyles; new and old (1970s) housing developments, based on Kawana Waters, Sunshine Coast Regional Council.

- "Greenhaven", a middle suburb, largely residential with low quality and ageing housing stock; largely rental accommodation including public housing; low lying and flood prone; based on Deception Bay, Moreton Bay Regional Council. 


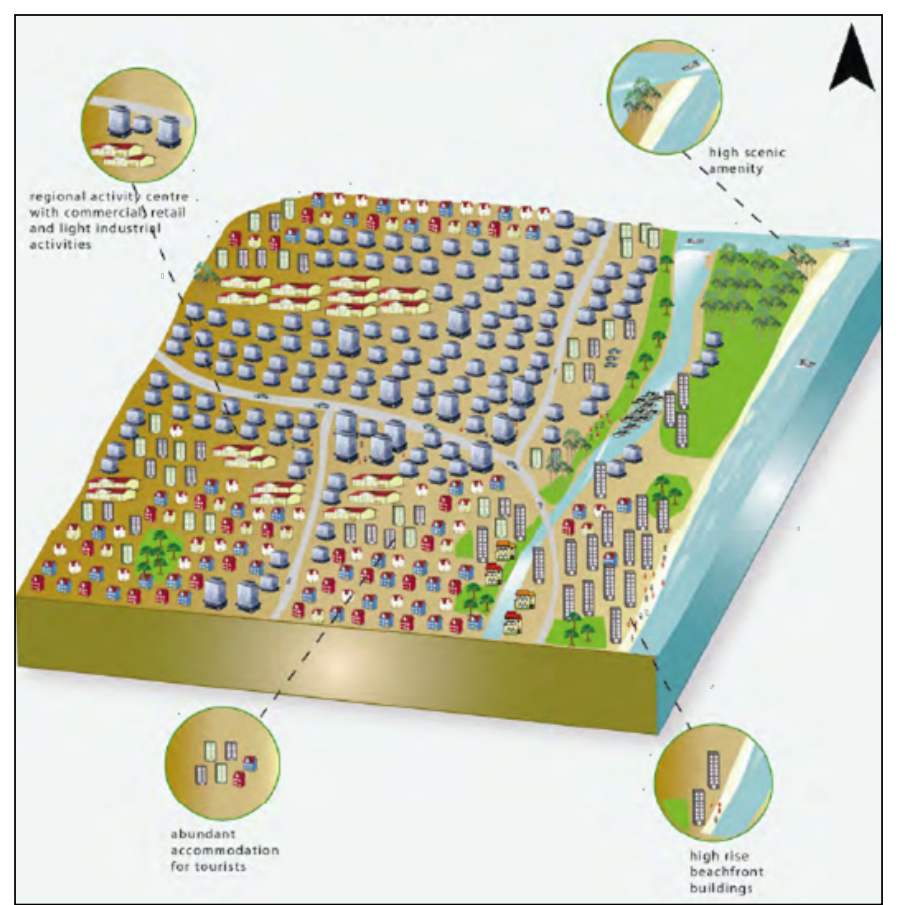

Figure 6. Three dimensional map describing "Sandy Shores", a hypothetical location based on the Gold Coast suburbs of Main Beach, Southport and Labrador.

Adaptation options included a range of options from a range of sectors involved in the research. Tested adaptation options relevant to the coastal management sectors were the following:

- Coastal defence programme: implement a programme of defence (storm surge barriers, seawalls and coastal dunes) to provide continuing flood risk management due to storm tides and sea level rise by controlling water levels within waterways.

- Beach nourishment strategy: beach nourishment and dune restoration are periodically executed to maintain beach width and a safety buffer against the most extreme storms and rising sea levels.

- $\quad$ Planned retreat - encourage the landward sitting and relocation of public and private assets in areas adjacent to receding shorelines.

- Full hazards disclosure clause: consider a Coastal Hazards Full Disclosure Law that alerts buyers of coastal property about current and future risks relating to extreme weather events and climate change such as erosion rates, storm history, inundation and sea level rise concerns.

- Building code design criteria: all new and substantially renovated buildings located along canals and waterways must provide for setbacks from the waterway and a freeboard above a projected site-specific flood level.

During the workshop, stakeholders were provided with addition information, including climate change storylines and sectoral factsheets. This information was used to select and test options by (and others, from other sectors) by (i) answering a range of questions and (ii) assess them against specific criteria. These criteria included: flexibility; robustness; equity; coherence/alignment (synergy) in terms of alignment and enhancement; acceptability (i.e. political, community, bureaucratic, and private sector acceptability); avoidance of maladaptation in terms of low greenhouse gas emissions; less vulnerable populations; low opportunity costs; adaptation incentives; and low path dependency. The details of the scenario planning process are available in a dedicated report (Low Choy et al. 2012). The information derived from this process was used to inform the development of an adaptation framework relevant to coastal settlements in South East Queensland. 


\section{Coastal adaptation framework}

Based on the outcomes of the scenario planning process, further stakeholder interviews and detailed investigations, a framework for adaptation was developed for South East Queensland, which includes a specific framework for the adaptation of coastal management. This framework is based on the overarching principle of adapting South East Queensland's coastal settlements to the risk of current and future coastal hazards. This principle is pursued by combining adaptation options to manage coastal erosion and floods with hard and soft defence infrastructure, planned retreat from areas at risk or changing design and improve resilience of buildings and infrastructure to accommodate floods. In addition, a specific policy is proposed to increase the capacity of coastal communities and institution to adapt to climate variability and change, including sea level rise. The adopted framework "Defend/Retreat/Accommodate" is widely used for coastal planning considerations (e.g. EUROSION, 2005) and was as used as set of sub-principles for a range of coastal management policies, programs and actions. In addition, a "Capacity Building" sub-principle encloses a range of policies, programs and actions designed to improve the capacity of coastal communities and institutions to manage SEQ shorelines in a changing climate.

In developing the framework we thought that councils may choose to adopt a combination of different policies for a given coastal stretch. For instance, developed areas or critical infrastructure can be defended from storm tides by combining a suite of actions to avoid inundation; less developed areas threatened by erosion can use planned retreat as a long term policy to absorb the impacts of sea level rise; innovative design standard can allow the accommodation of floods and reducing the damages to properties and infrastructure. As a result we have selected a set of possible options, which were finally expressed in terms of policies, programs and actions and analysed within a sophisticated framework. This framework uses a multi criteria appraisal assessment of each program and action and identifies possible implementation mechanisms, responsibilities, locations, timing and linkages with other sectors, including elements to monitor their effectiveness.

Policies, programs and actions are structured around the following options: beach nourishment, innovative erosion control structures, dune construction and regeneration, storm tide barriers and dykes, planning methods to implement planned retreat (e.g. rolling easement, coastal setbacks, land purchase, etc.), making space for water, community engagement and education programs and capacity building of institutions (figure 6). A total of 5 policies, 11 programs and 46 actions were developed for coastal management adaptation. Details are available in Low Choy et al. (2012a)

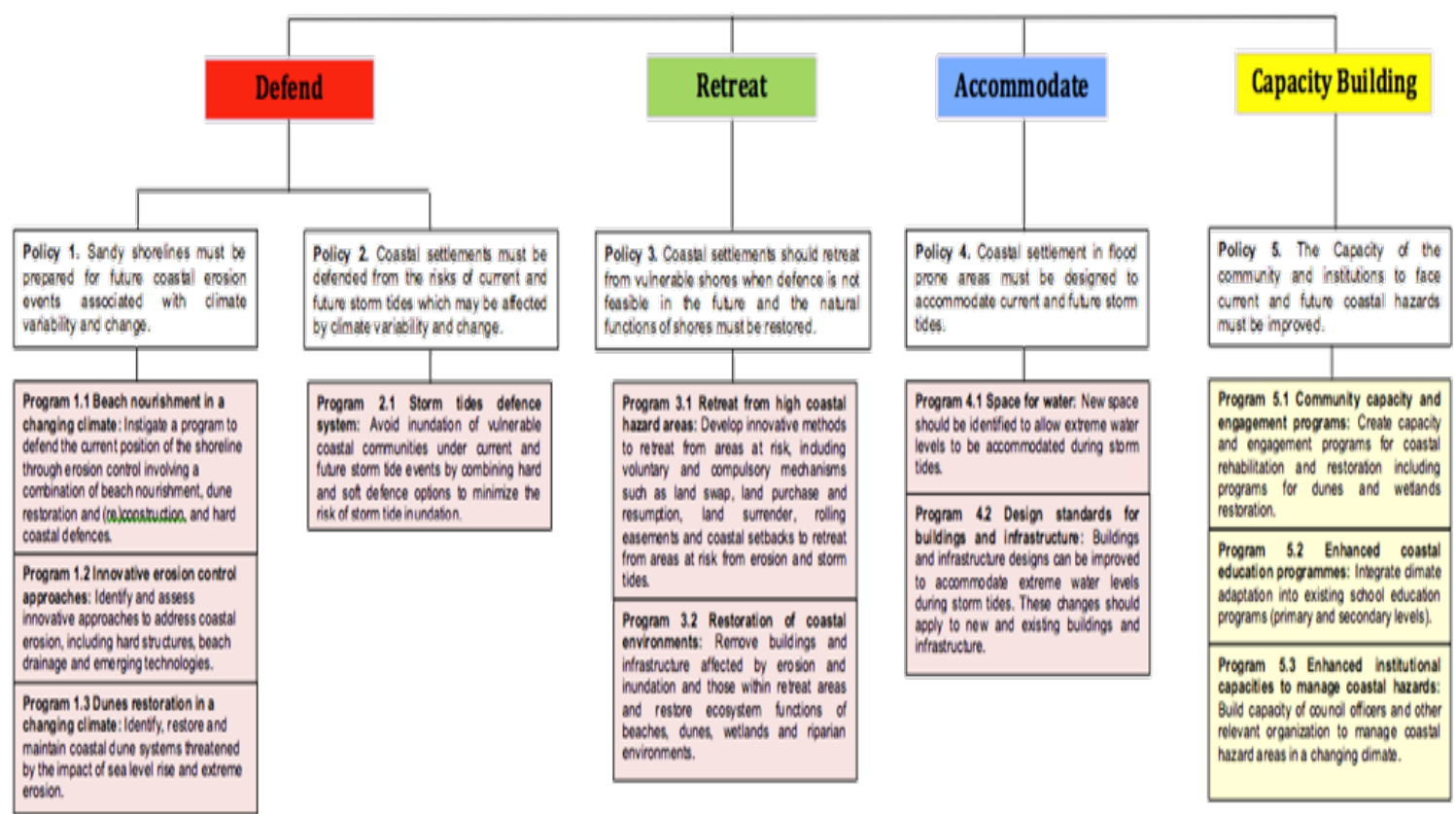

Figure 7. Framework for specific policies and programs for coastal adaptation, including 5 policies, 11 programs. 46 actions are then detailed under these programs in Low Choy et al., 2012a. 


\section{DELIVERING COASTAL ADAPTATION GUIDANCE FOR COUNCILS}

The outcomes of this research were useful to inform the development of a Compendium of Coastal Hazard Adaptation Options to be used by coastal councils across Queensland. (Sano et al. 2012). The Compendium was developed in the framework of the Queensland Coastal Plan (QCP) and the requirements to develop adaptation strategies for settlements within high hazard areas. This plan is currently under review by the new State Government (September 2012). The Compendium was developed to support decision processes by providing detailed information on a wide range of possible options to adapt to coastal hazards which were selected by stakeholders based on the list of options identified by our research (see table 1).

\begin{tabular}{|l|l|}
\hline \multicolumn{2}{|l|}{ Table 1. Options included in the Compendium of Coastal Hazard Adaptation Options for Queensland Coastal } \\
Councils & Option name \\
\hline Option type & 1.1 Beach nourishment \\
\hline 1. Regenerative options & 1.2 Dune construction and regeneration \\
& 1.3 Riparian corridor restoration and generation \\
& 1.4 Wetland restoration \\
\hline 2. Coastal engineering options & 2.1 Artificial reefs \\
& 2.2 Detached breakwaters \\
& 2.3 Groynes and artificial headlands \\
& 2.4 Sea dykes \\
\hline 3. Coastal settlement design options & 2.5 Seawalls \\
& 2.6 Storm surge barriers \\
\hline 4. Planning options & 3.1 Building retrofitting and improved design \\
& 3.2 Flood-resilient public infrastructure \\
& 3.3 Raise land levels \\
\hline & 4.1 Development setbacks \\
& 4.2 Land buy-back \\
& 4.3 Land swap \\
\hline
\end{tabular}

Each option expanded on specific elements of interest for Councils, including:

1. A technical description in relation to coastal hazards and management strategies;

2. An assessment of potential synergies or conflicts between options;

3. A description of the legal, administrative and planning framework for its implementation in Queensland;

4. A description of maintenance requirements, risks of failure and estimated costs; and

5. A multi-criteria overview of each option based on climate uncertainty, social, environmental and economic criteria.

The Compendium is intended to be used by coastal councils in Queensland to inform the process of developing a adaptation strategies within high hazard areas in the years to come, however it will also be of interest to other coastal councils in Australia and elsewhere.

\section{ACKNOWLEDGEMENTS}

This research was funded by the South East Queensland Climate Adaptation Research Initiative (Queensland Government, Commonwealth of Australia, CSIRO, Griffith University, University of the Sunshine Coast and University of Queensland), Queensland Smart State Future Coastlines, Modelling Impacts of Extreme Events on Coastal Environments (Griffith University, CSIRO, Australian Bureau of Meteorology and DHI) and the Coastal Adaptation Pathways project Coastal Hazard Adaptation Strategy for Townsville (Commonwealth of Australia, Queensland Government, Townsville City Council, LGAQ, executed by GHD and Griffith University)

\section{REFERENCES}

1. 1.Richards R., Sano, M., Roiko, A., Carter, R.W., Bussey, M., Matthews, J., Smith, T.F. (2012) Bayesian belief modeling of climate change impacts for informing regional adaptation options. Environmental Modelling \& Software, in press 
2. Abbs, D. (2009) Downscaling Tropical Cyclones for Climate Change Studies for the Australian Region, Personal Communication, CAWCR Modelling Workshop 2009: Modelling \& Understanding High Impact Weather.

3. Baum, S. (2004) 'Measuring socio-economic outcomes in Sydney: an analysis of census data using a general deprivation index', Australasian Journal of Regional Studies, Vol. 10, pp. 105- 133 .

4. Baum, S. (2008) Suburban Scars: Australian Cities and Socio-economic Deprivation, Urban Research Program, Research Paper 15, Griffith University, Brisbane.

5. Baum, S., Horton, S., Low Choy, D. \& Gleeson, B. (2009) Climate change, health impacts and urban adaptability: case study of Gold Coast City, Research Monograph 11, Urban Research Program, Griffith University (online), Available: http://www.griffith.edu.au/_data/assets/pdf___ file/0011/119864/urp-rm11-baum-et-al2009.pdf (20 May 2010).

6. Baum, S., Horton, S., Low Choy, D. \& Gleeson, B. (2009) Climate change, health impacts and urban adaptability: case study of Gold Coast City, Research Monograph 11, Urban Research Program, Griffith University

7. Castelle B, Corre Y, Tomlinson R. Can the gold coast beaches withstand extreme events? Geo-Marine Letters. 2007;28(1):23-30.

8. Crick F., Serrao-Neumann S., Low Choy D., Sano M., Baum S. (2011) A region at risk: policy determination through vulnerability hotspots assessment. In ICLEI (Ed) Resilient Cities 2011. Springer

9. Elias AA (2008) Towards a shared systems model of stakeholders in environmental conflict. International Transactions in Operational Research Volume 15, Issue 2, pages 239-253

10. EUROSION (2005) A European initiative for sustainable coastal erosion management www.eurosion.org

11. Giupponi, C., Mysiak, J., \& Sgobbi, A. (2008). Participatory Modelling and Decision Support for Natural Resources Management in Climate Change Research. FEEM Working Paper No. 13.2008

12. Godet M. (1994) From anticipation to action : a handbook of strategic prospective. UNESCO Pub., 283 p.

13. Hemer, M. , McInnes, K. \& Ranasinghe, R. 2009, Future Projections of the East Australian Wave climate, Proceedings of the 11th International Workshop on wave hindcasting and forecasting and coastal hazards, Halifax, Canada.

14. Holman IP, Rounsevell MD, Shackley S, Harrison P, Nicholls RJ, Berry PM, Audsley E (2005) A Regional, Multi-Sectoral and Integrated Assessment of the Impacts of Climate and Socio-Economic Change in the UK. Climatic Change, 71(1-2), 9-41.

15. IPCC 2007, Climate Change 2007: Impacts, Adaptation and Vulnerability. Contribution of Working Group II to the Fourth Assessment Report of the Intergovernmental Panel on Climate Change, eds. M. Parry, O.Canziani, J. Palutikof, P.van der Linden \& C. Hanson, Cambridge University Press, Cambridge, UK, 976pp

16. Kjaerulff, U., Madsen, A., 2008. Bayesian networks and influence diagrams: A guide to construction and analysis, New York: Springer

17. Langlois, A. \& Kitchen, P. 2001, 'Identifying and measuring dimensions of urban deprivation in Montreal: An analysis of the 1996 census data', Urban Studies, vol. 38, pp. 119-139

18. Low Choy D., Silvia Serrao-Neumann, Florence Crick, Gemma Schuch, Marcello Sano, Rudi van Staden, Oz Sahin, Ben Harman and Scott Baum (2012a) Adaptation Options for Human Settlements in South East Queensland - Supplementary Report, South East Queensland Climate Adaptation Research Initiative, Griffith University.

19. Low Choy D., Silvia Serrao-Neumann, Florence Crick, Gemma Schuch, Marcello Sano, Rudi van Staden, Oz Sahin, Ben Harman and Scott Baum (2012) Scenario Planning for Climate Change Adaptation, South East Queensland Climate Adaptation Research Initiative, Griffith University.

20. Low Choy, D., Serrao-Neumann, S., Baum, S., Crick, F., Sano, M., van Staden, R., \& Haman, B., Schuch, G., \& Sharma, V. (2011) Hypothetical Case Study Elaboration, South East Queensland Climate Adaptation Research Initiative, Griffith University.

21. Lynam T, Jong WD, Sheil D et al. (2007) A Review of Tools for Incorporating Community Knowledge, Preferences, and Values into Decision Making in Natural Resources Management. Ecology And Society, 12(1) 
22. Nicholls RJ, Cazenave A. Sea-level rise and its impact on coastal zones. Science (New York, N.Y.). 2010;328(5985):1517-20.

23. Noble JC, Walker P (2006). Integrated shrub management in semi-arid woodlands of eastern Australia: A systems-based decision support model. Agricultural Systems, 88(2-3), 332-359.

24. NTC-BOM (2011) National Tidal Centre - Bureau of Meteorology. The Australian Baseline Sea Level Monitoring Project - Annual Sea Level Data Summary Report - July 2010 June 2011.

25. O’Brien, P, (2000), Scenario Planning - A Strategic Tool, Bureau of Rural Science, Department of Agriculture, Fisheries \& Forestry Australia, Commonwealth of Australia. Canberra $36 \mathrm{p}$

26. Peterson, G.D., Cumming, G.S. \& Carpenter, S.R. (2003), "Scenario Planning: a tool for conservation in an uncertain world". Conservation Biology, 17(2), pp 358-366

27. Preston, B., Smith, T., Brooke, T., Gorddard, R., Measham, T., Withycomber, G., McInnes, K., Abbs, D., Beveridge, B. \& Morrison, C. 2008, Mapping Climate Change Vulnerability in the Sydney Coastal Councils Group, Prepared for the Sydney Coastal Councils Group.

28. Queensland_Government (2008) Queensland's future population

29. Rygel, L., O'Sullivan, D. and Yarnal, B. 2006, 'A method for constructing a social vulnerability index: an application to hurricane storm surges in a developed country.' Mitigation and Adaptation Strategies for Global Change, Vol. 11, 3, pp. 741-764.

30. Sano M., Cross S., Sahin O., Tomlinson R., Harper B. (2012) Coastal Hazard Adaption Options. A Compendium for Queensland Coastal Councils. GHD, Griffith University, City of Townsville, LGAQ, Queensland Government, Commonwealth of Australia. 192 p.

31. Sano M., Golshani A., Splinter K., Strauss D., Tomlinson R. (2011) A detailed assessment of vulnerability to climate change in the Gold Coast, Australia. Journal of Coastal Research SI 64 pp 245-249, CERF

32. Sharples, C., Mount, R. \& Pedersen, T. (2009) The Australian Coastal Smartline Geomorphic And Stability Map Version 1: Manual And Data Dictionary, Report of the University of Tasmania for the Department of Climate Change and Geoscience Australia

33. Smith T, Preston B, Brooke C, Gorddard R, Abbs D, McInnes K, Withycombe G, Morrison C, Beveridge B, Measham T (2009). Managing Coastal Vulnerability: New Solutions for Local Government. In E. Moksness, E. Dahl, \& J. Stttrup (Eds.), Integrated Coastal Zone Management. Oxford, UK: Wiley-Blackwell

34. Trelolar P, Taylor D, Prenzler P. Investigation of wave induced storm surge within a large coastal embayment - Moreton Bay (Australia). In: Proceedings of 32nd Conference on Coastal Engineering, Shanghai, China, 2010.; 2010.

35. Voinov A, Bousquet F (2010). Modelling with stakeholders. Environmental Modelling Software, 25(11), 1268-1281

36. Walker P (1996) Resolving problems with INFLUENCE. In: Environment Yearbook 1997. Environs Australia, pp. 167-168.

37. Wang X., Stafford Smith M., McAllister R.R.J., Leitch A., McFallan S., Meharg S. (2010) Coastal inundation under climate change: a case study in South East Queensland. Report prepared for the South East Queensland Climate Adaptation Research Initiative. Published by CSIRO, Canberra. 